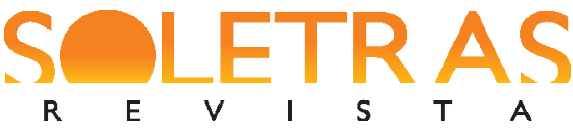

\title{
Figueiredo Pimentel: Contos da Carochinha e o nascimento da literatura infantil abrasileirada no final do século XIX
}

\author{
Cristina Rothier Duarte \\ Daniela Maria Segabinazi ${ }^{2}$
}

\begin{abstract}
Resumo: Nos estudos literários do século XIX, encontramos pesquisas acerca das obras de Figueiredo Pimentel mais relacionadas à sua produção para os adultos. Considerado bastante polêmico pelos temas abordados, esse autor desperta o interesse de investigadores da sociedade carioca da época. No tocante à literatura infantil brasileira, Figueiredo Pimentel é bastante citado na bibliografia histórica que se dedica aos estudos do nascimento dessa literatura em nosso país, contudo não encontramos informações que se detêm à investigação dessas obras. Desse modo, neste estudo, temos como objetivos fazer uma breve revisão bibliográfica sobre a vida e a obra do autor; e um estudo mais detido sobre o papel da obra Contos da carochinha (1894), considerada como a introdutória de uma literatura nacionalizada dirigida às crianças brasileiras no contexto social de então. Para tanto, fundamentamonos especialmente em Arroyo (2011), Zilberman (2016), Lajolo e Zilberman (1984). Como resultados, temos que a obra em tela, diferentemente, do acontecia com outras produções infantis da época, voltava-se mais para a apreciação estético-literária que para o pedagogismo, de maneira que, concluindo, notamos sua importância para historiografia literária nacional como uma obra que se destacou em seu tempo tanto por seu caráter literário, quanto pela popularidade que alcançou à época.
\end{abstract}

Palavras-chave: Figueiredo Pimentel. Contos da carochinha. Literatura infantil brasileira.

\section{Introdução}

A origem da literatura infantil e juvenil está intimamente relacionada à tradição oral. Os clássicos, como os contos recolhidos e registrados por Charles Perrault (1628-1703) e por Jacob Grimm (1785-1863) e Wilhelm Grimm (1786-1859), nos séculos XVII e XIX,respectivamente,apresentam-se como fruto da literatura popular e oral que circulava na Europa. Como não poderia ser diferente, no Brasil, a tradição oral de origem indígena, africana e europeia teve forte influência nas contações de histórias, conforme aponta Leonardo Arroyo,

[o]s leitores se limitavam aos livros religiosos e, quanto ao plano profano, à literatura oral, que veio naturalmente com os primeiros marinheiros portugueses e, aqui, foi acrescida da mitologia e das tradições indígenas,

\footnotetext{
${ }^{1}$ Mestranda do Programa de Pós-Graduação em Letras da Universidade Federal da Paraíba. E-mail: cristinarothier@hotmail.com.

${ }^{2}$ Professora Doutora do Departamento de Letras e do Programa de Pós-Graduação em Letras da Universidade Federal da Paraíba. E-mail: dani.segabinazi@gmail.com.
} 


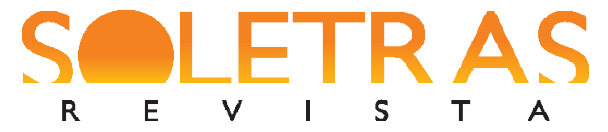

tendo sido, mais tarde, ambas as correntes enriquecidas pela contribuição africana. São, portanto, três as correntes culturais agindo no plano histórico da formação brasileira: a europeia, a indígena e a africana. (2011, p. 43-44). ${ }^{3}$

O processo de recolha dos contos populares orais pelos irmãos Grimm na Alemanha, de acordo com Guerreiro (2013), se dava por intermédio de pessoas de sua confiança que ficavam encarregadas de ouvir e tomar nota das histórias contadas por mulheres idosas, além de pessoas do círculo de amizade dos irmãos.

Também como resultado da recolha da tradição oral, além das traduções de Perrault e dos irmãos Grimm, em terras brasileiras, transitavam obras portuguesas, que eram lidas para o público jovem, como a de Gonçalo Fernandes Trancoso, Contos e histórias de proveito e exemplo, editada pela primeira vez em 1575 e compreendida como ñestórias colhidas diretamente da tradição popular portuguesa, influenciada pela árabe, e outras inspiradas nas obras de Caravaggio e Battiste Basileò (ARROYO, 2011, p. 24).

Em 1808, ao se estabelecer a Imprensa Régia, aqui, iniciava-se o processo de tradução de obras estrangeiras, possibilitando um maior, embora ainda bastante limitado, acesso à leitura, tanto pela escassa produção, quanto pela esporadicidade das publicações, como nos traz Lajolo e Zilberman (1984). Mas, no que diz respeito à literatura infantil brasileira registrada em suporte, deixando a esfera da oralidade, seus primórdios apontam para o final do século XIX, quando, em 1894, com a publicação de Contos da carochinha, Figueiredo Pimentel (1869-1914) reúne contos populares de variadas origens.Até então,predominavam, no Brasil, adaptações de contos europeus de edições francesas e portuguesas, fato que dificultava a recepção pelo leitor brasileiro, em razão do distanciamento da língua, que, embora, no caso do português, tivesse a mesma origem, configurava, culturalmente,como uma barreira para uma aceitação plena.

Nessa conjuntura, havendo a necessidade de adaptações de obras infantis para o português brasileiro, ñem fins do século XIX, já se iniciavam as primeiras recolhas da tradição oral com as edições de Pedro Quaresma. Assim, no ano de 1894, Figueiredo Pimentel lança os Contos da carochinha, recolhidos e adaptados da tradição oralò (FORMIGA, 2009, p. 68).O sucesso diante do público foi imediato, de forma que logo outras obras foram publicadas, totalizando dez títulos de acordo com o levantamento de Gilberto F. Pimentel,

\footnotetext{
${ }^{3}$ Em todas as citações utilizadas neste artigo, optamos por manter a grafia original das obras consultadas.
} 


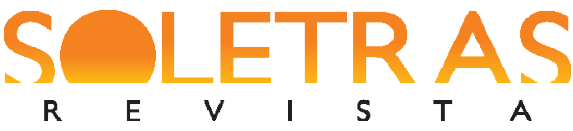

DOSSIÊï N. 34 ï 2017.2 ï CRISTINA ROTHIER DUARTE DANIELA MARIA SEGABINAZI

apontado por Arroyo (2011): Histórias da Baratinha, Histórias da Avozinha, Histórias de Fadas, Contos do Tio Alberto, Álbum de crianças, Os meus brinquedos, Histórias do Arco da Velha ${ }^{4} \mathrm{O}$ livro das crianças, Teatrinho infantil e Castigo de um anjo.

Seus livros ñcomeçaram a fazer um sucesso espantoso. Os que se importam, em linguagem diferente da que se dava no país, vão ficando sob a poeira das estantesò, assevera Luís Edmundo. Ao mesmo tempo, os livros de Figueiredo Pimentel subvertiam inteiramente como leitura os cânones da época, sobre serem escritos em linguagem solta, livre, espontânea e bem brasileira para o tempo. Foram livros que atravessaram os anos (ARROYO, 2006, p. 251).

Não obstante o caráter de importância das produções de Figueiredo Pimentel no cenário literário infantil brasileiro, esse autor é pouco estudado neste contexto, e disso decorre a necessidade de impulsionar pesquisas que busquem investigar os primórdios da literatura infantil produzida em nosso país. Nessa conjuntura, este artigo, além de realizar uma revisão bibliográfica sobre o autor e sua produção literária, dedica-se a um estudo mais detido na sua primeira obra para crianças, Contos da carochinha, publicada nos anos finais do século XIX pela Livraria Quaresma, a qual, embora revele uma nova literatura, mais próxima da cultura brasileira e já com indícios de afastamento do pedagogismo então em vigor, está esquecida.

\section{Figueiredo Pimentel: breve histórico da trajetória no jornalismo e na literatura para adultos}

Nascido em 11 de outubro de 1869, em Macaé, interior do Rio de Janeiro, Figueiredo Pimentel (Figura 1) iniciou sua vida profissional no jornalismo ainda jovem, mas foi nos idos de 1890 que se tornou bastante conhecido. Além da sua atividade no âmbito jornalístico nacional e internacional, como redator e colaborador, $\tilde{\mathrm{n}}$.... era quase impossível não se falar dele, pois parecia estar em todos os lugares ao mesmo tempo. [...] Estava presente nas

\footnotetext{
${ }^{4}$ É importante notar que de acordo com o prefácio da $1^{\mathrm{a}}$ edição de Histórias do Arco da Velha (1896), Olavo Guerra informa que a obra não fora escrita por Figueiredo Pimentel: ña série de obras para crianças, publicada pela Livraria do Povo, compõe-se das seguintes: Contos da Carochinha, Histórias do Arco da Velha, Histórias da Avózinha, Os meus brinquedos e Histórias da Baratinha. Dêsses, só o segundo não é de Figueiredo Pimentel. (GUERRA, [1896]/1958, p. 6).
} 


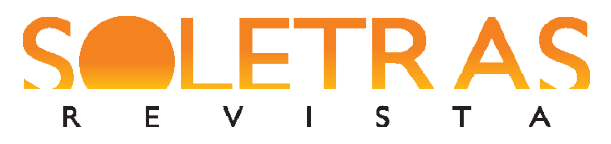

conferências literárias mais badaladas, nas redações dos principais jornais, nos aniversários e enterros de escritores, quando proferia discursosò (MENDES; LEITE, 2015, p. 118-119).

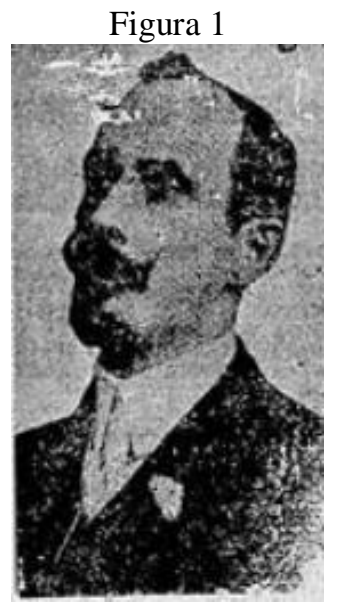

Fonte: $O$ Paiz, Rio de Janeiro, $\mathrm{n}^{\circ}$ 10714, 06 fev. 19145.

Antes de trabalhar nas produções infantis, adaptando clássicos europeus e reunindo contos populares, Figueiredo Pimentel publicou várias obras, enveredando tanto no gênero poético, com Fototipias (1893), Livro mau (1891), Amor (1896); quanto em prosas naturalistas: $O$ aborto (1893), Um canalha (1895), Suicida! (1895) e O terror dos maridos (1896). Devemos notar que sua obra não se resume aos títulos mencionados: $\tilde{n}[\mathrm{e}] \mathrm{m} 28$ de janeiro de 1898, a Gazeta da Tarde computava em 27o número de obras escritas por Figueiredo Pimentel, que tinha, então, 29 anos. Tal capacidade de trabalho, diziam os jornais, só era comparável à de Coelho Neto (1864-1934), outro prolífico escritor esquecidoò (MENDES; LEITE, 2015, p. 119).

No entanto, no final da década de 90 do século XIX, Figueiredo Pimentel reservou-se às produções para a infância e à sua atividade como cronista na coluna ñ́Binóculoò, do periódico Gazeta de Notícias, este, já no início do século XX (MENDES; LEITE, 2015). De acordo com Góes (2015), a coluna se estruturava em fragmentos diversos, mas poderia, a depender da importância da temática tratada, assumir contornos de crônica: ñ[u]m recurso usado com regularidade para ambientar o leitor no dia enfocado era iniciar o texto com a descrição do tempo (cronos)ò (GÓES, 2015, p. 24). Publicada aos domingos em cores, tratava

\footnotetext{
${ }^{5}$ Disponível em:

<http://memoria.bn.br/DocReader/docreader.aspx?bib=178691_04\&pasta=ano\%20191\&pesq=figueiredo\%20pi mentel>. Acesso em: 08ago. 2017.
} 
de assuntos da sociedade, abordando notícias sobre os últimos acontecimentos, ocupando-se também de literatura (BROCA, 1975). Além disso,

\begin{abstract}
[s]e dedicava excepcionalmente a aconselhar pessoas a seguir determinadas regras de comportamento e moda, ou seja, o que usar, onde usar, como usar, principalmente como agir em lugares públicos, em especial, nos ambiente da Avenida central. A coluna fez tanto sucesso que os jornais adotaram em suas folhas sessões semelhantes, viviam a observar os comportamentos das pessoas e determinar regras de etiqueta na alta sociedade, como padrão a qualquer cidadão (NUNES, 2009, p. 67).
\end{abstract}

Desse modo, Figueiredo Pimentel ñ...] tornou-se, a partir de 1907, o óráculo da belezaô ditava moda, fazia advertências, ministrava curso de como usar luvas... Todo carioca distinto, elegante e bem informado lia ñBinóculoò (DIDIER, 2005, apud SANTOS, 2013, p. 135). Não obstante o seu destaque como colunista social, nem sempre fora tido como elegante. Pelo contrário, suas obras naturalistas ensejavam na sociedade carioca uma impressão polêmica, muitas vezes, pornográfica, no entanto essa ideia a respeito de Figueiredo Pimentel, para o livreiro Pedro Quaresma, proprietário da editora que publicou obras naturalistas do autor como $O$ aborto (1893), bem como a coleção da Biblioteca Infantil, como Contos da carochinha entre outros, apresentava-se mais como uma promessa de vendagem e de popularização:

A má fama pregressa do escritor e a possibilidade de comercializar obras naturalistas na faixa do livro popular e pornográfico eram incentivos para se arriscar na empreitada. A partir de janeiro de 1893, o livreiro começou a anunciar em notas nos jornais da cidade o lançamento do ñempolgante romance naturalistaò de Figueiredo Pimentel (MENDES, 2016, p. 183).

Afora a sua atuação no ñBinóculoò, na década de 1880, Figueiredo Pimentel colabora de formas variadas para o jornal fluminense Província do Rio, apresentando como alguns de seus pseudônimos: Albino Peixoto, do folhetim $O$ artigo 200; Chico Botija, da coluna ñEntre as X e as XI; Abelhudo, dos artigos గ̃̃ara as moçasò; Tesoura, da seção ñChá de garfoò; e Heitor Vasco, das colunas de poesias (PIMENTEL, 2015, apud VEIRA, 2015). 
Após a passagem pelo Província do Rio, Figueiredo Pimentel prosseguiu na carreira de escritor e jornalista em diversos jornais da capital federal. $\mathrm{Na}$ década de 1890, a profusão de seus trabalhos literários ganhou repercussão na opinião pública. Em 1891, no cargo de redator de $O$ País, ao lado de colegas de trabalho como o escritor e jornalista maranhense Coelho Neto (1864-1934), Figueiredo Pimentel ampliou suas relações sociais entre os homens de letras e efetuou negócios promissores num mercado editorial em expansão (A Notícia 06 a07/02/1914, p. 1). (VIEIRA, 2015, p. 104).

Figueiredo Pimentel, assim, era ñum escritor profissional que escrevia, entre outras coisas, romances naturalistasò (MENDES; LEITE, 2015, p. 120). No entanto, concentrar-nosemos em suas publicações para crianças, notadamente, a primeira obra Contos da carochinha (1894), publicada pela Editora Quaresma, dada sua importância no cenário da literatura infantil nacional.

\section{Fontes literárias para crianças brasileiras até Figueiredo Pimentel e os Contos $\mathrm{da}$ carochinha inaugurando a literatura infantil brasileira para o deleite}

No século XIX, as obras literárias para crianças que aqui circulavam, ou eram de origem europeias escritas predominantemente em francês, ou vinham de Portugal (HOHLFELDT, 2010). Tais produções tratavam-se de recolhas de contos populares realizadas por Charles Perrault, na França; por Jacob e Wilhelm Grimm, na Alemanha; por Hans Christian Andersen (1805-1875), na Dinamarca; além de Guerra Junqueiro Francisco (1850-1923), Adolfo Coelho (1847-1919) e Teófilo Braga (1843-1924), em Portugal, entre outros.

Como não poderia deixar de ser, a repercussão das obras europeias para o público infantil foi tanta que várias edições se espalharam pelo mundo e chegaram a suas colônias. No cenário brasileiro, a produção literária infantil iniciou-se, juntamente com a produção didática, a partir do final do século XIX, tendo em vista o processo de modernização pelo qual o país passava, o que provocou, no âmbito educacional, a preocupação acerca da formação de cidadãos críticos e civilizados. ñNos moldes de nossa tradição de transplante cultural, também aqui, como não poderia deixar de ser, o desenvolvimento da literatura infanto-juvenil se liga às necessidades crescentes de escolarização, decorrentes da industrialização/urbanização e do aumento populacional [...] ò (MAGNANI, 2001, p.86). Desse modo, levando em consideração o interesse público na instrução da população, o ponto de partida para esse processo seria, naturalmente, a educação infantil. 


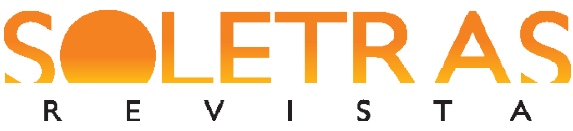

No campo literário, devido ao predomínio de obras europeias em francês e português de além-mar, ñ[a] criança não apenas se confundia com as palavras e o estilo grotesco desses livros, como, frequentemente, tinha dificuldade até mesmo de compreendê-losò (HALLEWELL, 2012, p. 306). Nessa conjuntura, havendo a necessidade de adaptações de obras infantis para o português brasileiro, Figueiredo Pimentel apresenta-se, nos dizeres de Arroyo (2011), como o instaurador da literatura infantil sob uma orientação que se distinguia das demais obras, que circulavam até o momento, cujo objetivo era o pedagógico. ñCronologicamente, Figueiredo Pimentel instaura na literatura infantil brasileira ï que até então em sua forte maioria se manifestava por meio de livros presos e interessados ao sistema educacional do País ï uma nova orientação: a popularò (ARROYO, 2011, p. 249).

No mesmo sentido, Zilberman (2016) expressa esse caráter inovador da produção de Pimentel:

As obras até agora parecem não ter conseguido ï provavelmente porque não o desejassem $і ̈$ fugir do enquadramento pedagógico. Destinadas a crianças, algumas optaram de imediato pelo mercado escolar, outras acabaram por ser adotadas para uso em sala de aula. Para alterar o panorama, foi preciso o livreiro Pedro da Silva Quaresma decidir lançar uma coleção dirigida à infância, formada a partir da recolha de narrativas então em circulação de preferência oral (ou em livros impressos em Portugal). Assim, em 1894, o proprietário da Livraria Quaresma encomenda ao jornalista Figueiredo Pimentel (1969-1914) a escrita de uma coleção de contos para crianças. (ZILBERMAN, 2016, p. 37).

A popularidade dessas produções da Quaresma para crianças também é comprovada pela publicidade veiculada por periódicos como Gazeta de Notícias e $O$ Paiz, os quais faziam circular quase diariamente anúncios de venda das edições das obras infantis escritas por Figueiredo Pimentel. Tais propagandas, além de apresentar os títulos dos contos contidos no livro anunciado, exaltava a sua importância enquanto objeto de deleite para as crianças:

Os Contos da Carochinha, que ora apresentamos ao público, são estas histórias que todos nós ouvimos em pequeninos e que sabem todas as crianças de todos os países, é uma escolhida coleção de quarenta magníficos contos populares, que todas as mãis de família devem dar a seus filhos para lerem, afim de guia-los no caminho do bem e da virtude, alegrando-os e divertindo-os ao mesmo tempo. ${ }^{6}$

\footnotetext{
${ }^{6}$ Gazeta de Notícias, Rio de Janeiro, 15 jun. 1894. Disponível em: http://hemerotecadigital.bn.br/. Acesso em: 15 jan. 2017. 


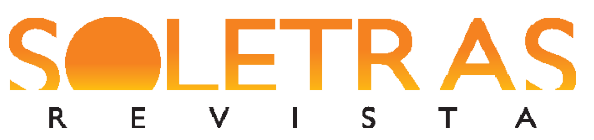

Além do fato de instaurar essa orientação inédita, a produção de Figueiredo Pimentel constitui-se como pertencente à fase de nacionalização da literatura infantil brasileira. Isso porque, até esse momento, como já dito, as obras destinadas às crianças que circulavam eram de origem estrangeira, e foi com o olhar atento dado pela Livraria Quaresma, quando ñPedro Quaresma Almeida encomendou ao escritor Figueiredo Pimentel, que já editara, em 1894, Contos da Carochinha, toda uma coleção de textos dirigidos a crianças brasileirasò (HOHLFELDT, 2010, p. 366), que se impulsionaram as publicações infantis nacionais. Assim, no mister de nacionalizar a literatura infantil brasileira, a partir de 1894, Figueiredo Pimentel passou a dedicar-se a adaptações de contos de Charles Perrault, dos Irmãos Grimm e de Hans Christian Andersen, mas seu trabalho não se limitou a trazer as obras desses escritores para o mundo literário infantil, ele também contribui criando seus próprios escritos, assim,

aproveitando-se do êxito editorial da fórmula europeia dos contos de fadas, decidira inventar o gênero brasileiro, ora publicando as obras de Grimm e Perrault reescritas com tintas de cores locais, ora organizando em texto as narrativas populares. A Biblioteca Infantil da Livraria do Povo compunha-se de brochuras de pequeno formato, assemelhando-se mais a folhetos de cordel; todas, porém, encapadas com cromos e gravuras. Os Contos da Carochinha, as Histórias da Avozinha e as Histórias da Baratinha alcançaram grande êxito entre a criançada, e sucessivas tiragens para Pedro da Silva Quaresma (LEÃO, 2007, p.18).

Suas obras, caracterizadas por uma linguagem espontânea, diferenciava-se, nesse aspecto, do que circulava para as crianças naquela época, e distanciava de temáticas de exaltação à pátria e de cunho pedagógico. Em Contos da Carochinha, ño leitor pode encontrar histórias de fadas europeias, ao lado de narrativas coletadas entre descendentes dos povoados do Brasil. Há histórias de origem portuguesa e também narrativas contadas pelas escravas que cuidavam das crianças brasileiras no século XIXò (BARBOSA, 2009, p. 13).

No prefácio da vigésima quinta edição da obra, publicada em 1958, o editor anuncia que Figueiredo Pimentel, ao reunir os contos em sua obra,

[...] prestou relevante serviço à juventude. Lendo alguns dêles em francês, espanhol, italiano, alemão e inglês, colhendo outros diretamente da tradição oral, contou-os a seu modo, em linguagem fácil, estilo correntio sem têrmos bombásticos e rebuscados, como convém, para o fim a que é a obra destinada ([EDITOR], 1958a, s.p.). 


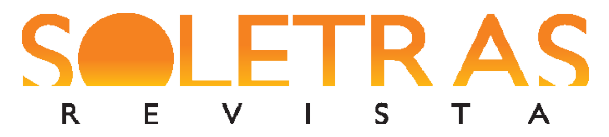

E de fato, tanto que o sucesso alcançado por Contos da carochinha fez com que se esgotasse em menos de um mês da publicação da primeira edição ([EDITOR], 1958a, p. 8). Ademais, já contando com a repercussão da vendagem dessa obra, a ela seguiram outras que fizeram parte da Biblioteca Infantil da Livraria Quaresma, como: Contos da baratinha, Contos da Avozinha, Álbum de crianças, Os meus brinquedos, Teatrinho infantil entre outros. A receita para o espetacular êxito dava-se, pois

[o]s livros de Pedro Quaresma eram particularizados, já que o editor decidiu por realizar uma série de modificações nas obras, desde a seleção de textos, privilegiando histórias que despertassem maior identificação no público infantil brasileiro, como também na linguagem, forma e abordagem dos materiais. Sob o ponto de vista comercial, os livros se tornaram mais baratos, tornando-se também mais atrativos, e a inserção de gravuras e ilustrações encantavam ainda mais crianças e adultos interessados em uma história intrigante, com seres místicos e mundos imaginários (BORGES; SANTOS, 2008, s.p.)

A edição de Contos da carochinha que estudamos foi publicada em 1958, apresenta uma capa (Figura 2) cuja moldura delimita uma série de informações: o título, nome do autor, a editora e local, os destinatários seguidos de uma curta apresentação: ñLivros para crianças contendo maravilhosa coleção de contos populares morais e proveitosos de vários países, traduzidos uns e outros apanhados da tradição oralò (PIMENTEL, 1958, capa).

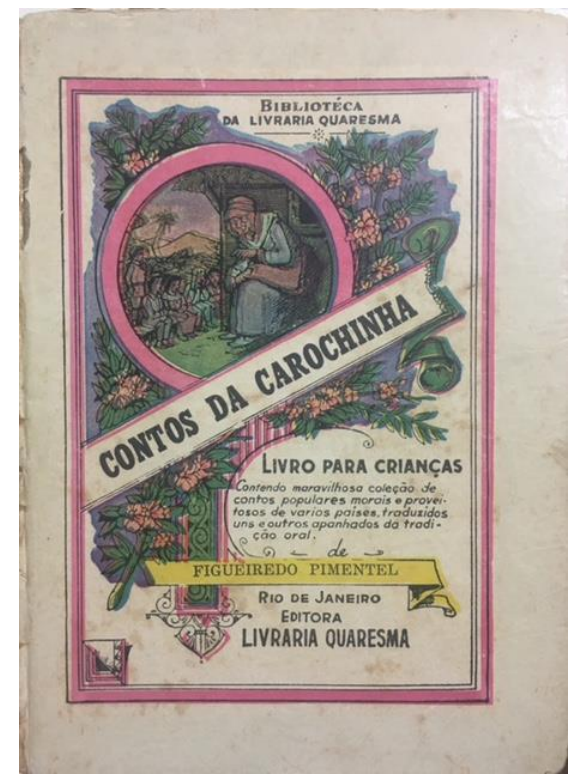

Figura 2

Fonte: Acervo particular 
A folha de rosto repete algumas das informações contidas na capa, com exceção da apresentação, que é substituída em seus termos: ñEscolhida coleção de sessenta e um contos populares, morais e proveitosos, de vários países, traduzidos e recolhidos diretamente da tradição oral.ò (PIMENTEL, 1958, folha de rosto), Além de informar a edição e o ano de publicação.

Após, há uma dedicatória à Maria de SantôAna, e, na página seguinte, um prefácio à edição que antecede o primeiro dos sessenta e um contos. Devemos notar que a edição em tela amplia a primeira edição, tendo em vista que esta apresentava quarenta contos como podemos perceber a partir do anúncio em Gazeta de notícias:

Os editores Quaresma \& C. acabam de publicar os Contos da Carochinha esplendida collecção de 40 contos populares; moraes e proveitosos de vários paizes; os Contos da Carochinha são essas historias que todos nós ouvimos em pequeninos, contadas por nossas mãis, nossos avós e velhos parentes, e que sabem todas as crianças de todos os paizes; escriptos em linguagem facil, como convém ás crianças os Contos da Carochinha são pois um livro valioso, um livro eterno, porque no Brazil até hoje nada se tem publicado que o iguale, elles são eternos, datam de seculos e seculos durarão ainda. ${ }^{7}$

Entre os contos apresentados na vigésima quinta edição, podemos destacar como clássicos universais: ñJoão e Mariaò, ño Barba Azulò, ñO gato de botasò, ñChapeuzinho vermelhoò, ñO pequeno polegarò, ñA gata borralheiraò, ñA Bela e a Feraò.

Acerca do estilo de Figueiredo Pimentel percebe-se, a priori, uma aproximação maior, quanto aos clássicos europeus, das versões romantizadas dos irmãos Grimm. Em ñChapeuzinho Vermelhoò, por exemplo, o final se apresenta como uma mistura dos desfechos das duas versões dos folcloristas alemães:

O caçador meteu-lhe duas pedras na barriga, e em seguida coseu a pele, ocultando-se depois com a avó e a neta.

Quando o lôbo acordou, devorado por uma sêde ardente, dirigiu-se para o tanque.

Enquanto caminhava ouviu as pedras batendo lá dentro, e ficou pasmado, sem saber o que era.

Chegando ao tanque, arrastado pelo pêso das pedras, afogou-se (PIMENTEL, 1958, p. 83).

\footnotetext{
${ }^{7}$ Gazeta de Notícias, Rio de Janeiro, 8 jun. 1894. Disponível em: <http://memoria.bn.br/DocReader/DocReader.aspx?bib=103730_03\&PagFis=9977\&Pesq=elles\%20s\%C3\%A3o $\% 20$ eternos, $\% 20$ datam $\% 20 \mathrm{de} \% 20$ seculos $\% 20 \mathrm{e} \% 20$ seculos $\% 20$ durar $\%$ C3\%A3o\%20ainda>. Acesso em: 8ago. 2017.
} 
A versão ainda não adaptada de Le petit Chaperon rouge, de Charles Perrault (16281703), por exemplo, termina com a menina sendo comida pelo lobo mau: ñEt, em disant ces mots, ce méchant loup se jeta sur le petit Chaperon rouge et lamangeaò (PERRAULT, 1994, p. 12). ${ }^{8}$ Diferentemente das narrativas reunidas por Perrault, as dos irmãos Grimm, em razão da consolidação do conceito de infância e do Romantismo, são mais amenas quanto à violência e à crueldade. Em Chapeuzinho Vermelho, por exemplo, há a presença do caçador que, percebendo um barulho estranho no interior da casa da avozinha, dá conta de que ele havia comigo a avó, de maneira que abre a sua barriga para salvá-la:

Ele deve ter comido a avó, pensou, e talvez ainda seja possível salvá-la, por isso é melhor não atirar. Então, buscou a tesoura e cortou a barriga do lobo. Assim que dei os primeiros cortes, avistou o chapeuzinho vermelho brilhando, e depois de mais uns cortes a menina saltou para fora dizendo: ñNossa, que susto. Estava tão escuro na barriga do loboò. Logo depois, a avó também saiu com vida. Chapeuzinho correu para buscar pedras bem pesadas, que eles colocaram na barriga do lobo, e, quando ele acordou e quis ir embora, as pedras pesavam tanto que acabou caindo morto.

Os três ficaram muito felizes. O caçador tirou a pele do lobo, a avó comeu o bolo e bebeu o vinho que Chapeuzinho levara e Chapeuzinho Vermelho, que estava feliz por ter escapado, prometeu a si mesma: ñDe agora em diante, não vou mais sair do caminho nem entrar na floresta sozinha, quando a minha mãe não deixarò (GRIMM; GRIMM, 2012, p. 139).

Esse conto apresenta ainda uma outra versão da história publicada pelos Grimm na mesma obra. Nessa, o lobo não consegue fazer Chapeuzinho desviar o seu caminho para a casa da avó, e ambas reunidas executam um plano contra o seu algoz, cujo final é assim:

Mas a avó percebeu a intenção dele. Diante da casa, havia um grande cocho de pedra e ela disse à neta: ñVá buscar o balde, Chapeuzinho Vermelho. Ontem cozinhei salsichas. Jogue a água na qual eu cozinhei as salsichas no cochoò A menina carregou a água até encher o cocho. O lobo sentiu o cheiro de salsicha e espichou tanto o pescoço atrás do cheiro que perdeu o equilíbrio, começou a escorregar do telhado e acabou caindo no cocho e se afogando. Chapeuzinho Vermelho voltou alegre e confiante para casa. (GRIMM; GRIMM, 2012, p. 140).

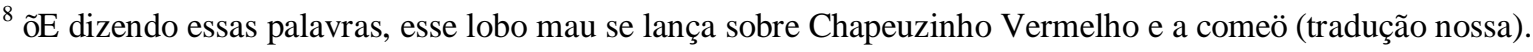




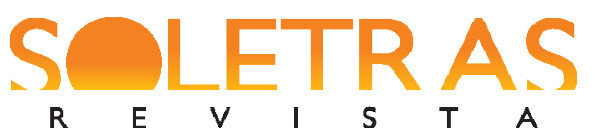

Como podemos perceber, são notórias as diferenças entre as versões dos contos dos séculos XVII e XVIII, e isso se dá principalmente em razão do tratamento que se conferia ao destinatário, a criança, cuja concepção operada com a ascensão burguesa parte de mudanças de pensamentos, antes voltados para o racionalismo iluminista, depois influenciados pelo Romantismo. E levando em consideração o contexto sócio histórico brasileiro, nada mais natural que a versão de Figueiredo Pimentel se aproximasse da dos irmãos alemães.

Salvo pequenas mudanças como essas, como a menina ser chamada de Albertina e apelidada como Naná, a estrutura geral do conto infantil permanece a mesma: a menina é convocada pela mãe para levar uma cesta contendo algo para comer e beber à sua avó que se encontra doente; ela desobedece à mãe, e, assim, encontra o lobo; o lobo devora a vovó e a menina; o caçador é atraído pelo ronco do lobo e salva ambas do mesmo modo que se dá na versão dos irmãos Grimm. Como se vê o propósito moralizante, reflexo dos princípios da época, continua o mesmo e o final permanece trágico para o lobo, no entanto feliz para a protagonista da história.

As publicações da Livraria Quaresma, mediante as adaptações de Figueiredo Pimentel, refletem um panorama histórico e social pertencente ao final do século XIX e vêm para atender um público específico que carece, até então, de obras nacionais com uma linguagem mais aproximada da sua realidade, bem como de uma leitura não obrigatoriamente destinada à educação, embora os prefácios e as propagandas da obra estejam implicados em sistema educacional. Endossando, assim, esse novo estilo, voltado mais para o deleite que para a educação $\ddot{i}$ mas ainda apregoando a moralidade, ambos pressupostos para aceitação do público da época, o editor da Livraria Quaresma, no prefácio da $1^{\text {a }}$ edição de Histórias da Avozinha (1959) / [1896], informa que గ̃[a]s crianças brasileiras, às quais destinamos e dedicamos esta série de livros populares, encontrarão mas Histórias da Avòzinha agradável passatempo, aliado a lições de moralidade, porque tais contos encerram sempre um fundo moral e piedosoò ([EDITOR], 1896). Ainda no tocante ao estilo das obras de Figueiredo Pimentel, Guerra, no prefácio da $1^{\mathrm{a}}$ edição, agora, da obra Histórias da Baratinha (1959)/[1896], afirma que

As velhas edições que existiam em língua portuguêsa eram pouco caprichosas, porque o estilo se ressentia do anonimato do autor, continham palavras obsoletas ou difíceis, e cenas imorais! Não exageramos. 
É necessário absoluto cuidado na escolha de livros destinados às crianças. Qualquer vocábulo, qualquer sentido, por maiores que sejam os circunlóquios, nelas desperta grande curiosidade. Tôda a simplicidade é pouca $і ̈$ demanda-se máxima pureza.

É porque são criteriosamente escritos os livros da BIBLIOTECA INFANTIL, que os venho recomendar às mães de família. (GUERRA, 1896, p. 8).

E no prefácio de Teatrinho Infantil (1955)/[1897], Figueiredo Pimentel adverte no prefácio que

É pura e simplesmente um livro para crianças. Escrevi-o obedecendo a um único fito $\ddot{i}$ divertir, deleitar a infância. Sendo, porém, uma obra infantil, moral, como convém, não deixa de ser didática, por que trata-se de uma coleção de pequenas peças teatrais, destinadas a serem representadas pelos meninos de ambos os sexos, de tôdas as idades, a mais tenra, até quase a juventude (PIMENTEL, 1955 [1897], p. 5).

De acordo com tais prólogos, observamos que os termos ñdivertirò e ñdeleitarò mostram claramente o caráter lúdico da literatura, e, portanto, revelam uma preocupação estética compatível com a época. Por outro lado, temos indícios que nessas obras havia a preocupação em ensinar e moralizar, tais advertências, contudo, estavam mais para satisfazer o público destinatário que para atender os referidos fins, de maneira que é possível perceber uma visão de literatura voltada para o deleite, sobretudo, quando Pimentel (1897) na passagem citada enuncia o pedagogismo em um sentido amplo, no sentido de que ñ[s] e a infância é um período de aprendizagem [...] toda mensagem que se destina a ela, ao longo desse período, tem necessariamente uma vocação pedagógicaò (SORIANO, 1975, apud COELHO, 2000, p. $31)$.

\section{Considerações finais}

Em um contexto em que nossas crianças tiveram acesso a uma literatura a elas destinada por meio de edições estrangeiras, notadamente francesas e portuguesas, a falta de proximidade vocabular e, até mesmo cultural, causava dificuldade de aceitação, de maneira que se fazia premente a publicação de obras nacionais com as quais os pequenos pudessem se identificar e, consequentemente, compreendê-las de uma forma mais espontânea. Diante 


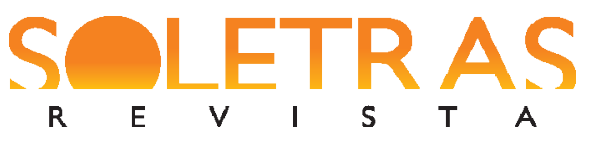

disso, Figueiredo Pimentel, a serviço da Livraria Quaresma, empreendeu esforços no sentido de reunir contos clássicos como os de Perrault, dos irmãos Grimm, de Andersen, além de histórias da tradição portuguesa e as contadas pelas amas de leite.

Esse papel desempenhado pelo escritor, jornalista, cronista fluminense, fê-lo reconhecido pela historiografia da literatura infantil nacional, sendo constante a citação de seu nome, quando nos remetemos a estudos que tratam dos primórdios dessa literatura em nossas terras. Não obstante as menções existentes, notamos sua brevidade frente à sua importância para a compreensão do contexto e das características de sua obra, sobretudo, no que diz respeito à nacionalização da literatura infantil, trazendo traços culturais e concernentes à linguagem local, além da popularização das obras devido à publicidade operada nos jornais da época e dos preços acessíveis oferecidos pela Livraria Quaresma.

Como pudemos perceber, mais que nacionalizar, Figueiredo Pimentel com apoio da Livraria Quaresma, compôs uma coleção destinada às crianças, que, apesar da proximidade com a literatura escolar, como bem apresenta Zilberman (2016), revelava traços de uma literatura mais autônoma e com características próprias, criando, assim, uma conjuntura favorável, tanto no âmbito editorial, quanto no que diz respeito ao público destinatário, para os seus sucessores.

\section{Referências}

ARROYO, Leonardo. Literatura brasileira. São Paulo: Editora Unesp, 2011.

BARBOSA, Ângela Márcia Damasceno Teixeira. Antigos contos, novas histórias na literatura infantil brasileira. Revista Travessia, Paraná, v. 3, n 3, p. 11-22 ,2009. Disponível em: <http://www.unioeste.br/prppg/mestrados/letras/revistas/travessias/ed_007/LINGUAGEM/An tigos\%20Contos.pdfhttp://www.unioeste.br/prppg/mestrados/letras/revistas/travessias/ed_007 /LINGUAGEM/Antigos\%20Contos.pdf>. Acesso em: 24 ago. 2015.

BORGES, Aline Danielle Batista; SANTOS, Ilzani Valeria dos. A livraria Pedro Quaresma e o mercado de livros infantis: a constituição de um novo público leitor. V Congresso Brasileiro de História da Educação. Aracaju, 2008.

BROCA, José Brito. A vida literária no Brasil ï 1900. Rio de Janeiro: Livraria José Oympio Editora S.A., 1975.

COELHO, Nelly Novaes. Literatura infantil: teoria, análise, didática. São Paulo: Editora Moderna, 2000. 


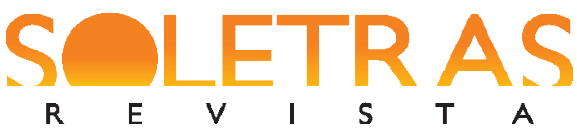

[EDITOR]. Prefácio. In: PIMENTEL, Figueiredo. Contos da Carochinha. São Paulo: Editora Quaresma, 1958a [1894].

Prefácio. In: PIMENTEL, Figueiredo. Histórias da Avozinha. São Paulo: Editora Quaresma, 1958b [1896].

FORMIGA, Girlene Marques. Adaptação de clássicos literários: uma história de leitura no Brasil. Tese de Doutorado em Letras, Programa de Pós-Graduação em Letras da UFPB, João Pessoa, 2009.

GÓES, Fred. O carnaval elegante de Figueiredo Pimentel. Textos Escolhidos de Cultura e Arte Populares, v. 12, n. 2, 2015. Disponível em:

<http://www.e-publicacoes.uerj.br/index.php/tecap/article/view/16474>. Acesso em: 19 ago. 2017.

GRIMM, Jacob; GRIMM, Wilhelm. Contos maravilhosos infantis e domésticos. Ilustração J. Borges. Tradução Christine Röhring. São Paulo: Cosac Naify, 2012.

GUERRA, Olavo. Prefácio. In: PIMENTEL, Figueiredo Histórias da Baratinha. São Paulo: Editora Quaresma, 1958 [1896].

GUERREIRO, Carla Alexandra. Contos da Infância e do Lar: da Tradição Oral à Literatura para a Infância. Álabe, Almería, v. 8, p. 1-12, 2013. Disponível: http://revistaalabe.com/index/alabe/article/view/160. Acesso em: 20 mar. 2017.

HALLEWELL, Laurence. O livro no Brasil: sua história. Tradução Maria da Penha Villalobos, Lólio Lourenço de Oliveira e Geraldo Gerson de Souza. São Paulo: Editora da Universidade de São Paulo, 2012.

HOHLFELDT, Antonio. Na história das publicações brasileiras, a criança também teve vez... In BRAGANÇA, Aníbal; ABREU, Márcia. HOHLFELDT. Impresso no Brasil: dois séculos de livros brasileiros. São Paulo: Editora Unesp, 2010, p. 363-380.

LAJOLO, Marisa; ZILBERMAN, Regina. Literatura infantil brasileira: história e histórias. São Paulo: Ática, 1984.

LEÃO, Andréa Borges. Publicar Contos de Fadas na Velha República: um compromisso com a nação. Revistas do Departamento de Comunicação e Artes da ECA/USP, São Paulo, Ano XII, nº 3, p. 15-22 set/dez. 2007. Disponível em:

<http://www.revistas.usp.br/comueduc/article/view/37654/40368>. Acesso em:01 out. 2015.

MAGNANI, Maria do Rosário Mortatti. Leitura, literatura e escola. São Paulo: Martins Fontes, 2001.

MENDES, Leonardo; LEITE, Paola Oliveira. As trajetórias de Suicida!(1895) e O terror dos maridos (1896), romances naturalistas esquecidos de Figueiredo Pimentel. Revista Soletras, n. 


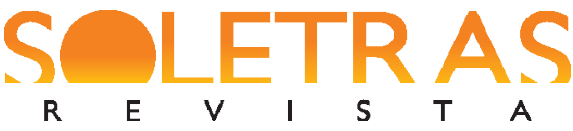

30 ,

DOSSIÊï N. 34 ï 2017.2 ï CRISTINA ROTHIER DUARTE

DANIELA MARIA SEGABINAZI

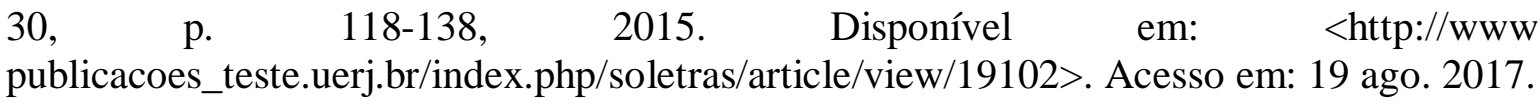

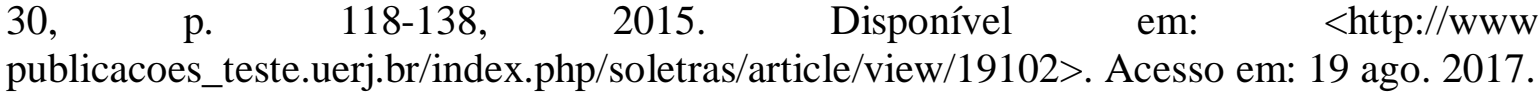

.Livros para homens: sucessos pornográficos no Brasil no final do século XIX. Cadernos do IL, n. 53, p. 173-191. 2016. Disponível em: <http://www.seer.ufrgs.br/cadernosdoil/article/view/67571>. Acesso em: 26 ago. 2017.

NUNES, Radamés Vieira. Sobre crônicas, cronistas e cidade: Rio de Janeiro nas crônicas de Lima Barreto e Olavo Bilac: 1900-1920. 2009. Disponível em: <https://repositorio.ufu.br/bitstream/123456789/16349/2/parte\%202.pdf>. Acesso em: 26 ago. 2017.

PERRAUlT, Charles et al. Contes de Charles Perrault et autres contes. Paris: Éditions de la Fontaine au Roy, 1994.

PIMENTEL, Figueiredo. Contos da Carochinha. São Paulo: Editora Quaresma, 1958a [1894].

Histórias da Avozinha. São Paulo: Editora Quaresma, 1958b [1896].

Histórias da Baratinha. São Paulo: Editora Quaresma, 1958c [1896].

SANTOS, Heloisa Helena Meirelles dos. Escola normal do Distrito Federal: por trás da modernidade civilizatória da cidade do Rio de Janeiro (1911-1920). Revista Contemporânea de Educação, v. 8, n. 15, 2013, p. 133-153. Disponível: <https://revistas.ufrj.br/index.php/rce/article/view/1690/1539>. Acesso em: 26 ago. 2017.

VIEIRA, Renata Ferreira. Figueiredo Pimentel e o romance $O$ aborto (1893): uma história pouco conhecida do naturalismo no Brasil. Revista Soletras, n. 30, p. 103-117, 2015. Disponível em: <http://www.e-publicacoes_teste.uerj.br/index.php/soletras/article/view/ 18482>. Acesso em: 26 ago. 2017.

ZILBERMAN. Leitura para a infância no século XIX brasileiro. Fronteira Z. Revista do Programa de Estudos Pós-Graduados em Literatura e Crítica Literária, n. 17, p. 22-42, 2016. Disponível em: <https://revistas.pucsp.br/index.php/fronteiraz/article/view/29413>. Acesso em: 01 ago. 2017.

\section{Figueiredo Pimentel: Contos da carochinha and the birth of the nineteenth- century Brazilian childrenô literature}

Abstract: In the nineteenth-century literary studies, we find research on the works of Figueiredo Pimentel which are more related to its production for adults. Considered quite controversial due to the themes he addressed, this author arouses the interest of researchers of the society of Rio de Janeiro. Regarding Brazilian children's literature, Figueiredo Pimentel is well-quoted in the historical bibliography dedicated to the study of the birth of this literature in our country; however we donâ find information that pertains to the investigation of these 


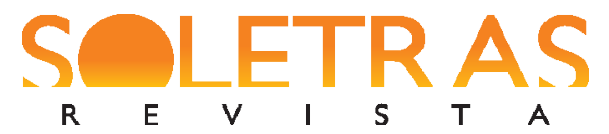

works. Thus, in this study, we aim to make a brief bibliographic review about the author's life and work; and a more detailed study about the role of Contos da carochinha (1894), considered as the introductory of a nationalized literature directed at Brazilian children in the social context social of the time. To do so, we are especially based on Arroyo (2011), Zilberman (2016) and Lajolo \& Zilberman (1984). As a result, we have that the work on canvas, unlike that of other children's productions of the time, turned more to the aestheticliterary appreciation than to pedagogism, so that, and to conclude, we note its importance for national literary historiography as a work that stood out in its time as much for its literary character, as for the popularity it reached at the time.

Keywords: Figueiredo Pimentel. Contos da carochinha. Brazilian chidrenôs literature.

Recebido em: 30 de agosto de 2017.

Aprovado em: 11 de outubro de 2017. 